\title{
Spatial and Temporal Dynamics of Mal Secco Disease Spread in Lemon Orchards in Israel
}

\author{
Miriam Ben-Hamo, David Ezra, Helena Krasnov, and Lior Blank ${ }^{\dagger}$ \\ Department of Plant Pathology and Weed Research, Agricultural Research Organization, Volcani Center, Rishon LeZion 7505101, Israel \\ Accepted for publication 8 December 2019.
}

\begin{abstract}
Mal Secco is a severe disease of citrus in which the fungus Plenodomus tracheiphilus (formerly Phoma tracheiphila) penetrates the vascular system of the host. In this study, we characterized the spatial dynamics of the disease in seven lemon orchards. A representative block of trees from each orchard was evaluated monthly during 3 consecutive years. In addition, scouts assessed disease severity in 75 orchards from three different geographical regions and tested for association between disease severity and measures of orchard management, environmental factors, cultural practices, and cultivar type. We assessed disease incidence and characteristics of spatial patterns using Ripley's $K$ function and fitted logistic regression models for different neighboring tree structures followed by model selection methods to provide insight into the spatial and temporal dynamics of disease progress. We found different rates of disease spread in different orchards, which are most likely the result of
\end{abstract}

ABSTRACT

One of the key goals of epidemiological research is to identify the variables affecting the spread or severity of diseases (Blank et al. 2016, 2019b; Campbell and Madden 1990; Firester et al. 2018). Studies based on large-scale surveys are not common for emerging infectious diseases (Meentemeyer et al. 2012) and typically focus on correlating disease incidence with environmental (e.g., soil type or $\mathrm{pH}$ ) and/or climatic conditions (Aguayo et al. 2014; Lamichhane et al. 2014). Only a few studies have explored the relationship between disease incidence and variability associated with the crop management practice, including rootstock and cultivar, or planting distance (Blank et al. 2016, 2019b; Shtienberg 1996; Thébaud et al. 2006). Even less common are studies that use a multiscale approach (Blank and Blaustein 2014; Blank et al. 2013) to study disease distribution (Blank et al. 2016, 2019b; Ostfeld et al. 2005).

Mal Secco is a severe disease of citrus targeting the vascular system of the host, and it is caused by the mitosporic fungus Plenodomus tracheiphilus (formerly Phoma tracheiphila) (de Gruyter et al. 2013; Nigro et al. 2011). It was first reported in 1894 on citrus growing on islands in Greece, but since that time, it has spread to almost the entire Mediterranean Basin and the Black Sea (Nigro et al. 2011). Field observations suggest that the most susceptible citrus species are lemon (Citrus lemon), citron (Citrus medica), and lime (Citrus aurantifolia), but almost all citrus species are susceptible when artificially inoculated (EPPO CABI 1997). An infected host shows a substantial reduction in crop yield, resulting in

†Corresponding author: L. Blank; liorb@volcani.agri.gov.il

Funding: This study is part of the Mal Secco project financed by the Israeli Ministry of Agriculture and Rural Development and Israeli Plants Production \& Marketing board project grant number 643010113.

*The $\boldsymbol{e}$-Xtra logo stands for "electronic extra" and indicates that supplementary material is published online.

The author(s) declare no conflict of interest.

(c) 2020 The American Phytopathological Society differences in orchard management practices or less likely the result of differences in climatic conditions. There was an indication that agricultural tools contribute to spread of the disease within rows of trees. The results confirm that the lemon cultivar Interdonato is less susceptible compared with other citrus cultivars, and they suggest that the density of urban terrain surrounding each orchard is positively correlated with the severity of the disease. In contrast to our expectations, no correlation was found between the density of lemon orchards surrounding an orchard and the severity of the disease within it, which corroborates previous findings regarding the limited distribution of the disease.

Keywords: citrus, ecology and epidemiology, land use, multiple regression model, Plenodomus tracheiphilus, Ripley's $K$

an economic impact to lemon production where the pathogen occurs (Migheli et al. 2009). Moreover, neither fungicidal nor other methods of control have proven efficacious, forcing growers to revert to less susceptible cultivars that are characterized by poor commercial quality with a reduced number of fruit compared with susceptible cultivars (Gulsen et al. 2007; Nigro et al. 2011). It was estimated that control of the disease would result in doubling of lemon production in affected regions (Cutuli 1985). In 2016, global lemon production was estimated to be 19 million tons, with $18 \%$ produced in regions affected by Mal Secco disease (Food and Agriculture Organization of the United Nations 2016). Phytosanitary regulations are imposed on fruit from countries in Mal Seccoendemic regions. Any exported fruit must originate in orchards free of Mal Secco disease, and the orchards must be at least $1 \mathrm{~km}$ from the nearest Mal Secco-diseased tree. These regulations have serious economic implications for countries where the disease has been detected (D. Ezra, personal communication).

The epidemiology of Mal Secco was described previously (Migheli et al. 2009; Nigro et al. 2011). Briefly, spores are dispersed from pycnidia on infected plant tissue by wind and rain, and they can infect leaves, branches, or other plant parts on the same or nearby trees. Infection occurs at temperatures between 14 and $28^{\circ} \mathrm{C}$ (Migheli et al. 2009). In Israel, infections commence in early spring (late March) and continue until the beginning of June. The spores germinate and penetrate the host through wounds (EPPO CABI 1997). The newly developed mycelia enter a dormant stage that ends when temperatures rise in the spring to early summer (Nigro et al. 2011). At this stage, the pathogen penetrates the xylem and grows basipetally through the host branches into the main trunk of the tree, eventually reaching the roots. During midsummer, when temperatures are $>28^{\circ} \mathrm{C}$, fungal growth ceases. Infected trees begin to show symptoms of the disease during spring and early summer. Disease progress is usually renewed during late summer when the temperatures again fall below $28^{\circ} \mathrm{C}$ (Nigro et al. 2011). Between early November and the end of December, it becomes too cold $\left(<14^{\circ} \mathrm{C}\right)$ for the pathogen to develop further in the plant, and it produces pycnidia 
that will serve as the source for new infections the following season. Pycnidia are considered the primary mode of infection. Another spore type exists that is a secondary mode of infection. Production of "phialoconidia" is from the fungal mycelium within the xylem, and they are dispersed by the transpiration flow to remote, disease-free parts of the host, where they germinate and cause additional disease. This process occurs during growth of the mycelium from spring to the beginning of winter (Migheli et al. 2009). Thus, there can be more than one cycle of infection. Furthermore, in addition to the infection cycles that occur during the winter, newly appearing pycnidia in the autumn may serve as a source of infection at the beginning of the rainy season in Israel. The secondary mode has several cycles of infection during the mycelia growth period.

Controlled experiments have demonstrated that woody material found in the soil acts as a source of the inoculum for periods longer than 4 months, suggesting that material left on the ground following pruning can act as an inoculum source for weeks (De Cicco et al. 1984). Finally, fungal propagules were also detected in the first $10 \mathrm{~cm}$ of the soil layer, providing another potential source of inoculum (Licciardello et al. 2006; Russo et al. 2009).

Cultural practices are also relevant and can facilitate or prevent infection by $P$. tracheiphilus. For example, frequent irrigation combined with high levels of nitrogen fertilization favors disease spread, and soil tillage during periods when inoculum is abundant can increase the risk of root infection (Nigro et al. 2011; Ruggieri 1948; Raciti et al. 1990). However, refraining from soil tillage is also unfavorable because it allows roots to reach the upper layers of the soil, and thus, it exposes rootlets to the risk of infection by the fungal propagules found in the soil (Nigro et al. 2011). To prevent dispersal and spread of the disease, growers are recommended to remove and eliminate infected plant debris that falls to the ground following sanitation pruning because it can otherwise become a source of inoculum in the orchards. The timing of sanitation pruning is also critical, and it is advisable to prune repeatedly before disease symptoms become evident (Traversa
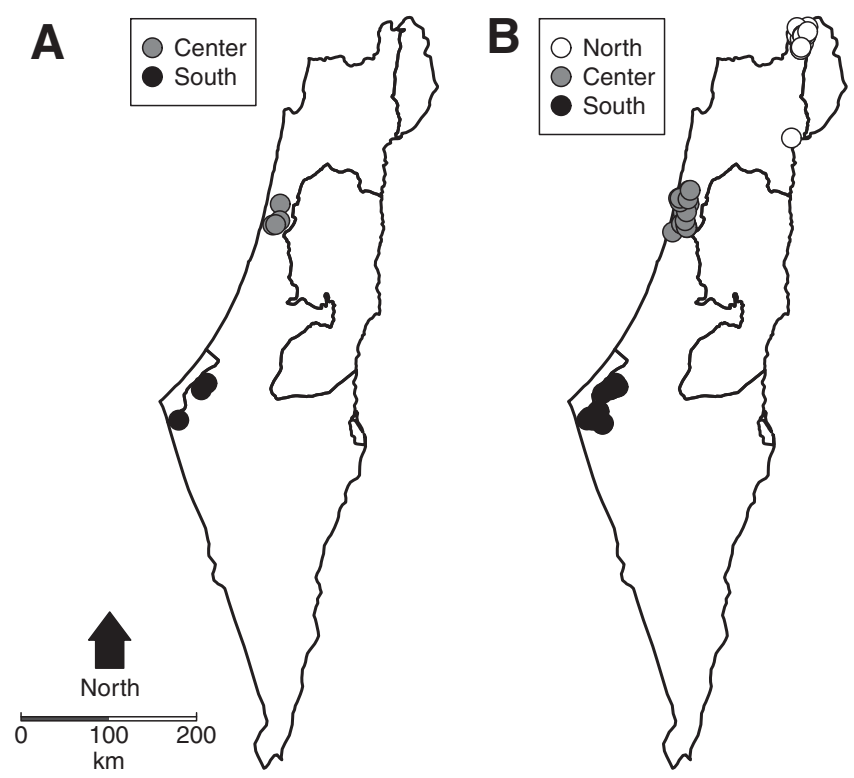

Fig. 1. Lemon and lime orchards surveyed for incidence and severity of Mal Secco disease. A, Study area of disease occurrence within orchards: light gray circles denote the four lemon orchards that were surveyed in the coastal plain of central Israel, and dark gray circles denote the three lemon orchards that were surveyed in the Negev Desert of southern Israel. B, Study area of disease occurrence in three different geographical regions: the white circles denote 23 lime orchards surveyed in the Hula Valley of northern Israel, the light gray circles denote 26 lemon orchards surveyed in the coastal plain of central Israel, and the dark gray circles denote 26 lemon orchards surveyed in the Negev Desert of southern Israel. et al. 1992). This is recommended especially for young trees. Sanitation pruning older, chronically diseased plants may result in more abundant vegetation and faster colonization of healthy branches because the disease cannot be completely eradicated from a tree (Nigro et al. 2011).

Studying spatial patterns of diseased plants over time can provide us with information about infection patterns, dispersal processes, and disease development as well as insight into the interaction of biological, physical, and environmental factors involved in shaping these processes (Blank et al. 2016). Our goal was to use statistical methods to quantitatively identify the spatial patterns of disease progress and thus, gain understanding of the biological and physical mechanisms underlying them. The specific aims were (i) to characterize the spatiotemporal dynamics of disease spread during 3 years, (ii) to identify cultural practices that may contribute to disease spread, and (iii) to identify physical and environmental factors that play a role in infection and disease dispersal.

\section{MATERIALS AND METHODS}

From 2015 to 2017, we assessed severity of Mal Secco at two different scales: (i) infected trees within orchards to investigate spatial and temporal dynamics of the disease within orchards and (ii) infected orchards in different geographical regions to characterize the effect of cultural practices and environmental factors on Mal Secco disease. All surveys were performed by field scouts trained to identify typical symptoms of Mal Secco: yellowing of leaves, shedding of leaves while leaf petioles remain attached to the branch, dead and dry branches with evidence of sectorial dieback, and trees with dead branches bearing mummified fruit. In cases where dead trees were present in the orchard, the following symptoms were evaluated: presence of mummified fruit, fungal fruiting bodies on dry tissue, and discoloration of the xylem in tree stumps (Migheli et al. 2009).

Spatial and temporal dynamics of the disease within orchards. We studied the spatial distribution and spatial dynamics of Mal Secco disease in four lemon orchards located in the coastal plain of central Israel and three lemon orchards located in the northwestern Negev Desert in southern Israel between 2015 and 2017 (Fig. 1A and Table 1). Once a month, the scouts surveyed a representative block of trees within each orchard that consisted of 10 rows, each with 20 to 30 trees.

Assessment of disease severity. Scouts visually estimated the severity of symptoms of Mal Secco on each tree using an ordinal scale with seven classes where $1=$ healthy tree, showing no signs of infected twigs or branches; $2=$ tree has a single diseased twig; $3=$ tree with several infected twigs; $4=$ tree with a single infected branch or five infected twigs; $5=$ tree with more than five infected branches and a thin tree crown; $6=$ tree is dead; and $7=$ uprooted tree. Uprooted trees were considered to be infected with $P$. tracheiphilus only if they originated from an infected plot having at least three of the symptoms of the disease as described in the previous section. In addition, we checked several trees in each plot for the presence of orange pigment in the xylem of diseased trees. Orange pigment in the xylem is a typical symptom of Mal Secco disease (Migheli et al. 2009). In most plots, we verified the presence of the pathogen in randomly chosen trees using PCR to detect P. tracheiphilus in samples of leaves, shoots, or the trunk following established protocol (Ezra et al. 2007). Samples for PCR were collected from live trees only because dead trees were either completely dry or uprooted and removed from the orchards. In each orchard, the scouts also interviewed the farmer to understand why the trees were uprooted and to determine whether they had exhibited symptoms of Mal Secco.

However, mild symptoms of Mal Secco may be easily confused with other disorders, including stress or frost. In addition, the PCR tests used to detect $P$. tracheiphilus of trees with mild symptoms 
were not conclusive. Because of these issues, we decided to conservatively define a tree with Mal Secco as one rated as class 5 or higher and distinguish it from healthy trees rated as class 4 or lower.

Estimating the rate of disease progress. To study disease progress in each of the orchards, we calculated disease incidence as the percentage of infected trees identified in each month. Although most infections with $P$. tracheiphilus occur during late autumn and winter, additional infection events are possible if inoculum and open wounds occur simultaneously throughout the season (Nigro et al. 2011). Therefore, we considered Mal Secco as a polycyclic disease, and we used a nonlinear least squares regression with a logistic fit to characterize the change in disease incidence over time. Next, a logit transformation of disease incidence was used to calculate the rate of disease progress $(r)$ in each of the surveyed orchards (Van der Plank 1963).

Spatial distribution pattern. To assess spatial distribution pattern in each orchard, Ripley's $K$ function (Blank et al. 2019a; Ripley 1976) was used, where each tree receives a value of $K(r)$ representing the number of neighboring infected trees in a radius $r$ calculated as follows:

$$
K(r)=\frac{a}{n(n-1)} \cdot \sum_{i, j} I\left(d_{i, j} \leq r\right) \cdot e_{i, j}
$$

where $a$ is the area of the sampled block of trees, $n$ is the number of infected trees in the block, and $I$ receives a value of zero or one to denote the presence of infected trees within radius $d$ of the focal tree. Radius $d$ is defined to be equal or smaller than radius $r$. Finally, $e$ is a function correcting for the outer limits of the tree block. We compared the calculated value of $K$ with a theoretical estimate of $K$, which assumes a random distribution of infected trees within each block. A calculated value of $K$ higher than the theoretical estimate is indicative of clusters of diseased trees.

Spatial dynamics. Finally, we assessed the spatial dynamics of disease progress in each of the orchards where an increase in disease incidence was observed over time and where we identified clusters of infected trees using Ripley's $K$ function. The goal was to distinguish between three different patterns of disease spread: (i) disease being transmitted within the tree rows, (ii) disease being transmitted across the tree rows, and (iii) omnidirectional patterns of disease transmission. To differentiate between these three patterns of disease spread, we followed a model selection approach and compared three different logistic regression models, each corresponding to one of the three different spatial patterns of disease transmission (Sparks et al. 2008). For each model, a logistic regression analysis was used to relate disease incidence in every tree with that of its neighboring trees. For each week $t$, let $Z_{t}(x)$ be the disease severity of an arbitrary focal tree at location $x$ within the block, and let $Z_{t}(x+1)$ and $Z_{t}(x-1)$ be those of its neighbors (depending on if it is within-row, between-row, or omnidirectional transmission that is been evaluated). The disease severity of the arbitrary tree $Z_{t}(x)$ is then regressed on the mean disease severity of the neighboring trees:

$$
\widehat{Z}_{t}(x)=\frac{1}{2} \cdot\left(Z_{t}(x-1)+Z_{t}(x+1)\right)
$$

To determine the appropriateness of the model, three goodness of fit parameters were used: the coefficient of determination $\left(R^{2}\right)$, the regression $P$ value, and the Akaike information criterion (AIC) value. The following packages were used in estimating the rate of disease progress and for the spatial dynamics analyses: "spatstat" (Baddeley et al. 2015), "pracma" (Borchers and Borchers 2019), "stringr" (Wickham 2010), "tidyr" (Wickham and Henry 2017), "GGally" (Schloerke et al. 2011), "lsmeans"
(Lenth and Lenth 2018), and "ggplot2" (Wickham 2016). All statistical tests were performed using $\mathrm{R}$ version 3.3.0 (R Core Development Team 2014), and all results are reported as means \pm 1 standard error.

Characterizing effects of cultural practices and environmental factors. The study area comprised 75 lemon and lime orchards, each of which were surveyed, from three distinct geographical regions in Israel: 23 lime orchards from the Hula Valley of northern Israel, 26 lemon orchards from the coastal plain of central Israel, and 26 lemon orchards from the northwestern Negev Desert in southern Israel between 2015 and 2017 (Fig. 1B). The severity of disease symptoms in the orchards and the association with cultural practices and environmental factors were explored by correlation analysis. Further details of the variables recorded for each orchard are listed below.

Assessment of disease severity. Scouts visited each orchard once a year during April and May. The scouts walked between the tree rows observing the canopy and looking for characteristic symptoms of Mal Secco disease. The number of randomly selected surveyed rows in each orchard was proportional to the size of the orchard (e.g., 4 rows were evaluated in a 10-row orchard, 8 rows were evaluated in a 20-row orchards, and so on). The severity of the disease was estimated for each orchard as a whole using a 7-class ordinal scale: $1=$ all trees observed as healthy, $2=\mathrm{a}$ few trees in the orchard with infected twigs, $3=$ trees with a few infected branches but no trees with many infected branches, $4=$ at least one tree with many infected branches but no dead or uprooted trees, $5=\leq 10 \%$ dead or uprooted trees, $6=10$ to $50 \%$ dead or uprooted trees, and $7=\geq 50 \%$ dead or uprooted trees.

Tree and location variables. Seventeen additional variables that might affect incidence and progression of Mal Secco were recorded for each of the 75 surveyed orchards. Since 2001, the effects of the landscape on species distribution in general (Atauri and de Lucio 2001; Blank and Blaustein 2012; Marmen et al. 2016) and specifically on infectious disease (Blank et al. 2019b; Meentemeyer et al. 2012; Ostfeld et al. 2005; Plantegenest et al. 2007) have received increased attention, demonstrating the impact of landscape composition on disease persistence and severity.

1. Geographical region. There were three distinct geographical regions: (i) the coastal plain in central Israel, which is characterized by Mediterranean climate of hot and dry summers and cool rainy winters; (ii) the Hula Valley in northern Israel, which is enclosed within two mountain ranges and is thus characterized by more extreme daily and seasonal temperature fluctuations than the coastal plain; and (iii) the Negev Desert in southern Israel, which is characterized by an arid climate (Goldreich 2003).

2. Area. The area of each orchard was measured in meters ${ }^{2}$ to allow for standardizing overall disease severity and progression in orchards of different size.

TABLE 1. Description of the seven plots of lemon used to study the withinorchard spatial and temporal dynamics of Mal Secco disease

\begin{tabular}{llcclc}
\hline Plot & Region & $\begin{array}{c}\text { Age } \\
\text { (years) }\end{array}$ & $\begin{array}{c}\text { Lemon } \\
\text { cultivar }\end{array}$ & Rootstock & $\begin{array}{c}\text { Spacing (between } \\
\text { row }[\mathrm{m}] \times \text { within } \\
\text { row [m]) }\end{array}$ \\
\hline 6024 & Center & 8 & Eureka Allen & NA $^{\mathrm{a}}$ & $5 \times 3$ \\
9080 & Center & 5 & Eureka Allen NA & $5 \times 3$ \\
9694 & Center & 24 & Eureka Allen NA & $6 \times 3$ \\
36030 & Center & 24 & Eureka Allen Khushkhash & $6 \times 3$ \\
8168 & Center & 17 & Eureka Allen & Volka & $7 \times 4$ \\
51083 & South & 18 & Eureka Allen Khushkhash & $6 \times 3$ \\
81340 & South & 8 & Eureka Allen & Volka & $6 \times 3$ \\
\hline
\end{tabular}

${ }^{a} \mathrm{NA}$, information was not available. 
3. Age. Time in years since the orchard was planted. Previously reported findings indicate greater disease susceptibility in young trees (Migheli et al. 2009).

4. Cultivar. The cultivar of the citrus species grown in the orchard. Cultivars may vary in susceptibility to Mal Secco disease (Solel and Oren 1975; Solel and Spiegel-Roy 1978).
5. Rootstock. The rootstock type of the citrus species grown in the orchard. Rootstock may affect susceptibility to Mal Secco disease (Solel and Oren 1975; Solel and Spiegel-Roy 1978).

6. Distance between rows. The distance in meters between adjacent rows.

\section{A}
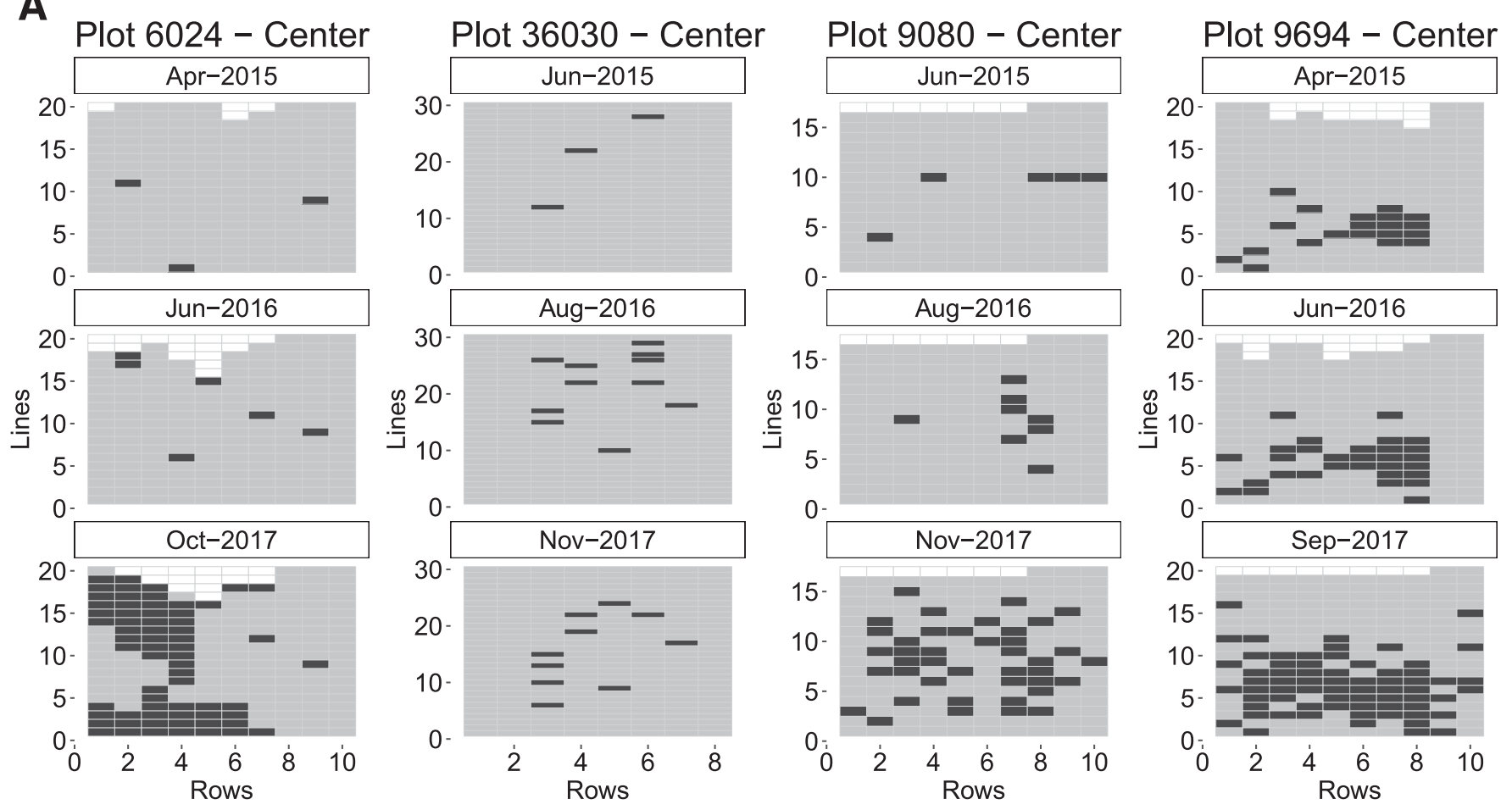

B
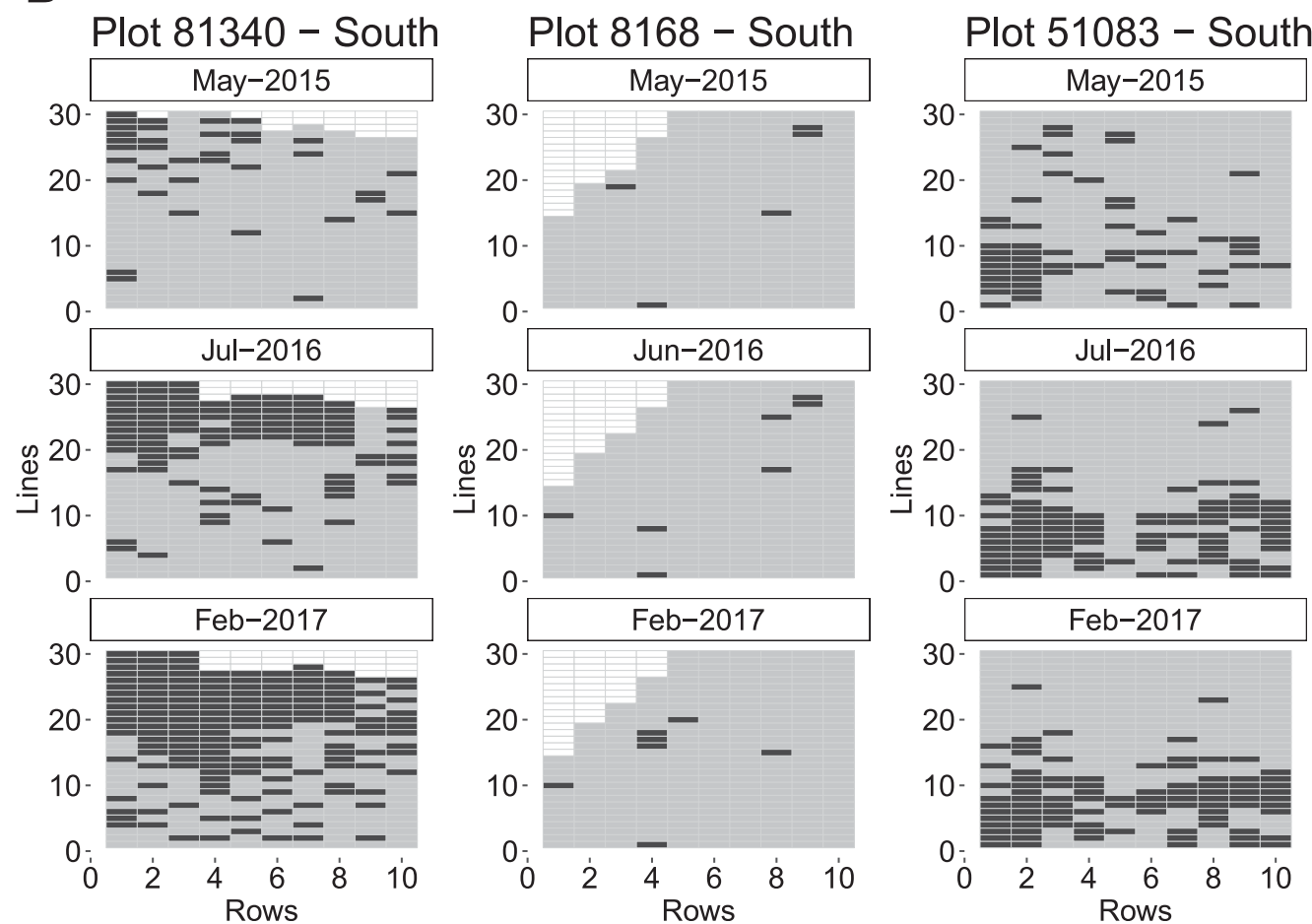

Fig. 2. The change in the number of citrus trees with symptoms of Mal Secco disease over the course of the study. The change in the number of infected trees at three representative assessment times in $\mathbf{A}$, four orchards from the coastal plain in central Israel and $\mathbf{B}$, three orchards from the Negev Desert in southern Israel. The three assessments represent the first month that each orchard was surveyed, the last month that each orchard was surveyed, and the middle month in the survey period. Each tile denotes either an infected tree (dark gray) or a healthy tree (light gray). White tiles denote either absent trees or trees that were not assessed at that time. 
7. Distance between trees within rows. The distance in meters between trees within the same row.

8. Number of irrigation lines. The number of irrigation lines per tree row. Orchards had rows with either a single irrigation line parallel to one side of the row or two irrigation lines parallel on either side of the row. Irrigation may affect the disease (Raciti et al. 1990; Ruggieri 1948).

9. Precipitation. The mean annual rainfall in millimeters was extracted from a raster data file $(1$ pixel $=300 \mathrm{~m})$ provided by the Israel Meteorological Service (Tel Aviv, Israel).

10. Elevation: Digital terrain model (DTM; 1 pixel $=25 \mathrm{~m}$ ) of Israel created by Hall (2008) was used to derive the elevation of each orchard. Elevation can affect both abundance and richness of fungal species (Fisher and Fulé 2004; Talley et al. 2002).

11. Slope: This DTM of Israel was also used to calculate the elevation difference between the highest and lowest points in each orchard as an estimate of orchard slope. The slope affects the amount of solar radiation striking the surface, which in turn, affects the temperature and soil moisture (Bennie et al. 2008).

12. Urban terrain. The total area of urban terrain within a radius of $500 \mathrm{~m}$ surrounding each orchard as extracted from a geographical information system (GIS) land use layer (1 pixel $=100 \mathrm{~m}$ ) obtained from the Ministry of Agriculture and Rural Development of Israel (Rishon LeZion, Israel).
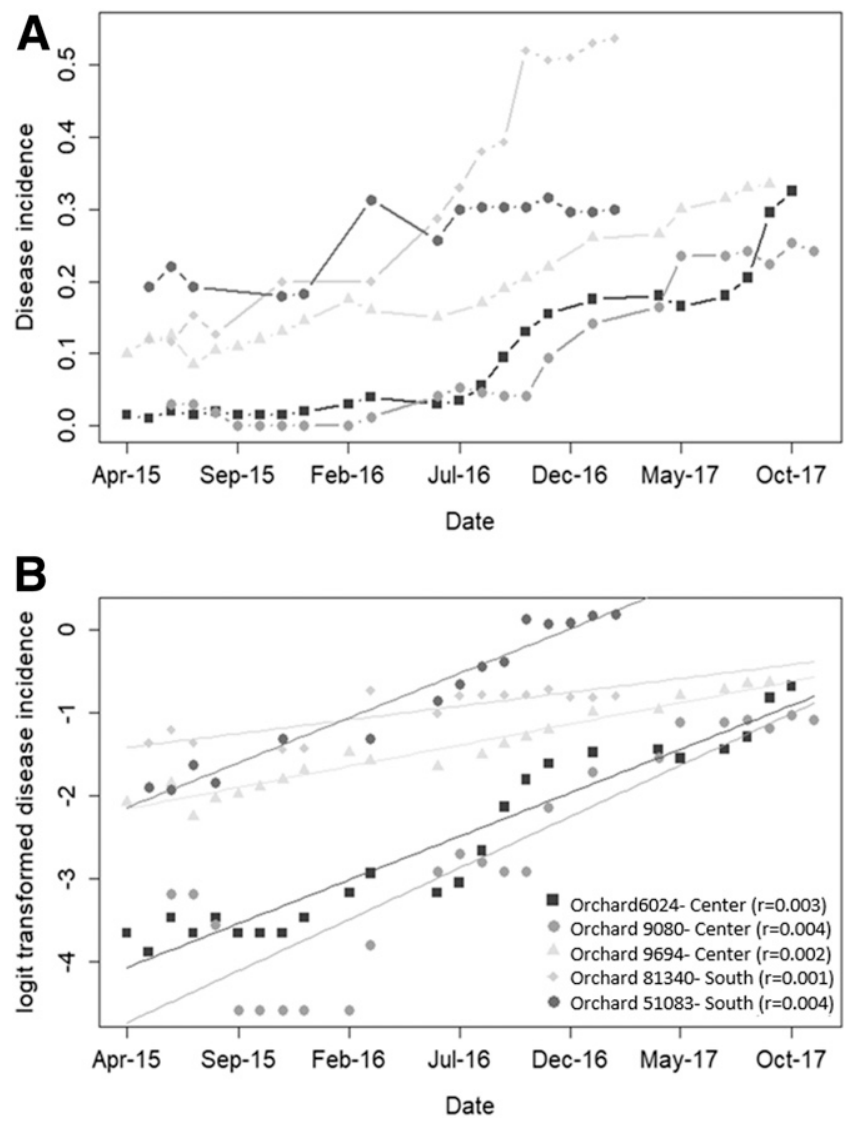

Fig. 3. The change in incidence of Mal Secco disease in orchards in Israel over the course of the study. A, The change in disease incidence (percentage of infected trees) over the course of the study for each of the five orchards for which disease incidence increased over time. B, The logit-transformed disease incidence over time including a linear regression solution for each of the five orchards. The value of the slope denotes the rate of disease progress $(r)$ for each orchard.
13. Plantations. The total area of deciduous and evergreen orchards within a radius of $500 \mathrm{~m}$ surrounding each orchard as extracted from a GIS land use layer $(1$ pixel $=100 \mathrm{~m}$ ) obtained from the Ministry of Agriculture and Rural Development of Israel.

14. Crop fields. The total area of crop field within a radius of $500 \mathrm{~m}$ surrounding each orchard as extracted from a GIS land use layer $(1 \mathrm{pixel}=100 \mathrm{~m}$ ) obtained from the Ministry of Agriculture and Rural Development of Israel.

15. Surrounding natural area. Total natural area within a radius of $500 \mathrm{~m}$ surrounding each orchard as extracted from a GIS land use layer $(1$ pixel $=100 \mathrm{~m})$ provided by the Ministry of Agriculture and Rural Development of Israel.

16. Citrus. The total area of citrus orchards within a radius of $500 \mathrm{~m}$ surrounding each orchard as extracted from the AgriTask online farm data management system of Israel (https:// www.agritask.com/index.html?dsf $\mathrm{x}=\mathrm{m}$; Tel Aviv, Israel).

17. Lemon orchards. The total area of susceptible citrus species (lemon, citron, and lime) within a radius of $500 \mathrm{~m}$ surrounding each orchard as extracted from the AgriTask online farm data management system of Israel.

A univariate analysis of variance was used to check if cultivar type was confounded by orchard age. Value of $<0.05$ was considered to be significant.

Multiple regression model analysis. Neter et al. (1989) suggested that multicollinearity is considered severe when the variance inflation factor (VIF) is $>10$. We calculated the VIF using the function "vif" from the R package "usdm" (Naimi et al. 2014). In the dataset, the highest VIF was greater than five. Next, we reduced the number of explanatory variables to seven by their importance to have at least 10 observations per variable. Two different criteria for ordering the explanatory variables were used by their importance. (i) The LMG (proposed by Lindemann et al. 1980) index was calculated using the function "calc.relimp" in the R package "relaimpo" (Grömping 2006); this index calculates the average $R^{2}$ value of all models for a specific number of variables and produces a value between zero and one. The LMG index represents the relative importance of each explanatory variable. (ii) The function "varImp" in the R package "caret" was used (Kuhn 2015) to calculate the relative importance of each explanatory variable; this function calculates the decrease in prediction power for the omission of a given explanatory variable from the model. Once again, each variable receives a standardized value between zero and one that represents its relative importance. Next, three models were generated to study the associations between the variables and disease severity: the LMG index model

TABLE 2. Pairwise comparisons of the rate of progress of Mal Secco disease in five citrus orchards in Israel

\begin{tabular}{lrlcrc}
\hline Contrast $^{\mathrm{a}}$ & \multicolumn{1}{c}{ Estimate $^{\mathrm{b}}$} & \multicolumn{1}{c}{$\pm \mathrm{SE}^{\mathrm{c}}$} & d.f. $^{\mathrm{d}}$ & $t$ statistic $^{\mathrm{e}}$ & \multicolumn{1}{c}{$P$ value } \\
\hline $6024-9080$ & -0.000623 & 0.000357 & 89 & -1.747 & $0.4111\left(\mathrm{NS}^{\mathrm{f}}\right)$ \\
$6024-9694$ & 0.001777 & 0.000361 & 89 & 4.925 & $<0.0001$ \\
$6024-51083$ & 0.002363 & 0.000494 & 89 & 4.789 & 0.0001 \\
$6024-81340$ & -0.000082 & 0.00048 & 89 & -0.171 & $0.9998\left(\mathrm{NS}^{\mathrm{f}}\right)$ \\
$9080-9694$ & 0.002400 & 0.000368 & 89 & 6.516 & $<0.0001$ \\
$9080-51083$ & 0.002986 & 0.000499 & 89 & 5.985 & $<0.0001$ \\
$9080-81340$ & 0.000541 & 0.000486 & 89 & 1.113 & $0.7994\left(\mathrm{NS}^{\mathrm{f}}\right)$ \\
$9694-51083$ & 0.000586 & 0.000502 & 89 & 1.167 & $0.7698\left(\mathrm{NS}^{\mathrm{f}}\right)$ \\
$9694-81340$ & -0.001860 & 0.000489 & 89 & -3.802 & 0.0024 \\
$51083-81340$ & -0.002446 & 0.000594 & 89 & -4.119 & 0.0008 \\
\hline
\end{tabular}

a The contrast denotes the two orchard identifications for which the rate of disease progress is being compared.

b The estimate is the rate of disease progress calculated as the slope in logittransformed disease incidence over time.

c SE, standard error for each estimate of rate of disease progress.

d d.f., degrees of freedom.

e The $t$ statistic and $P$ value were calculated using Tukey's post hoc method for multiple comparisons.

${ }^{f} \mathrm{NS}$, not significant. 
included the seven most important variables, the varImp model included the seven most important variables as indicated by their relative importance value, and a third model included the overlapping six variables of the two previous models. All three models were linear mixed effects models, where the identification number of each orchard was defined as a random factor and the assessment of disease severity in each plot was the dependent variable. Normal distribution was assessed using the Shapiro-Wilk test and quantile-quantile (QQ) plots. After a given explanatory variable was identified as significant, a Tukey's honestly significant difference (HSD) post
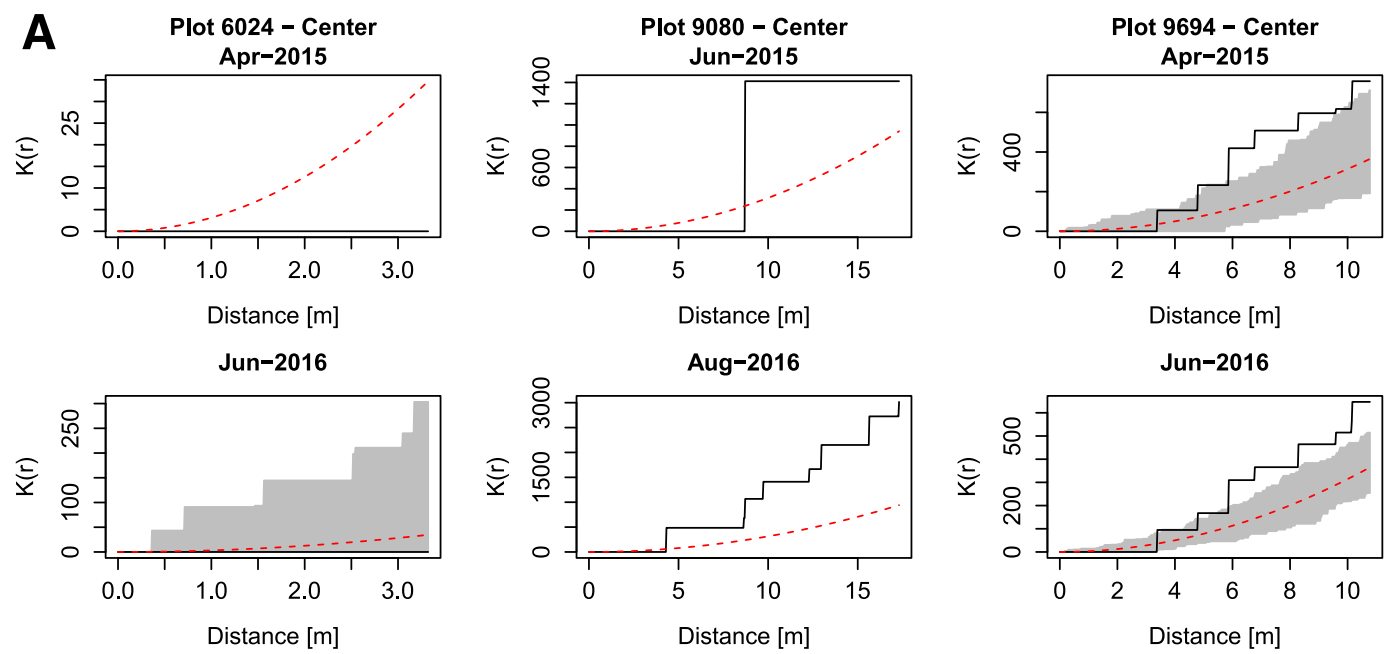

Oct-2017
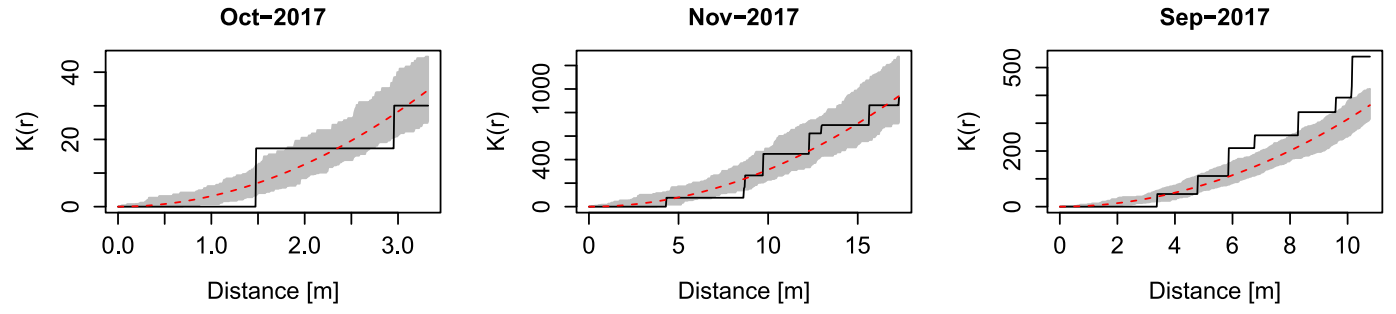

B
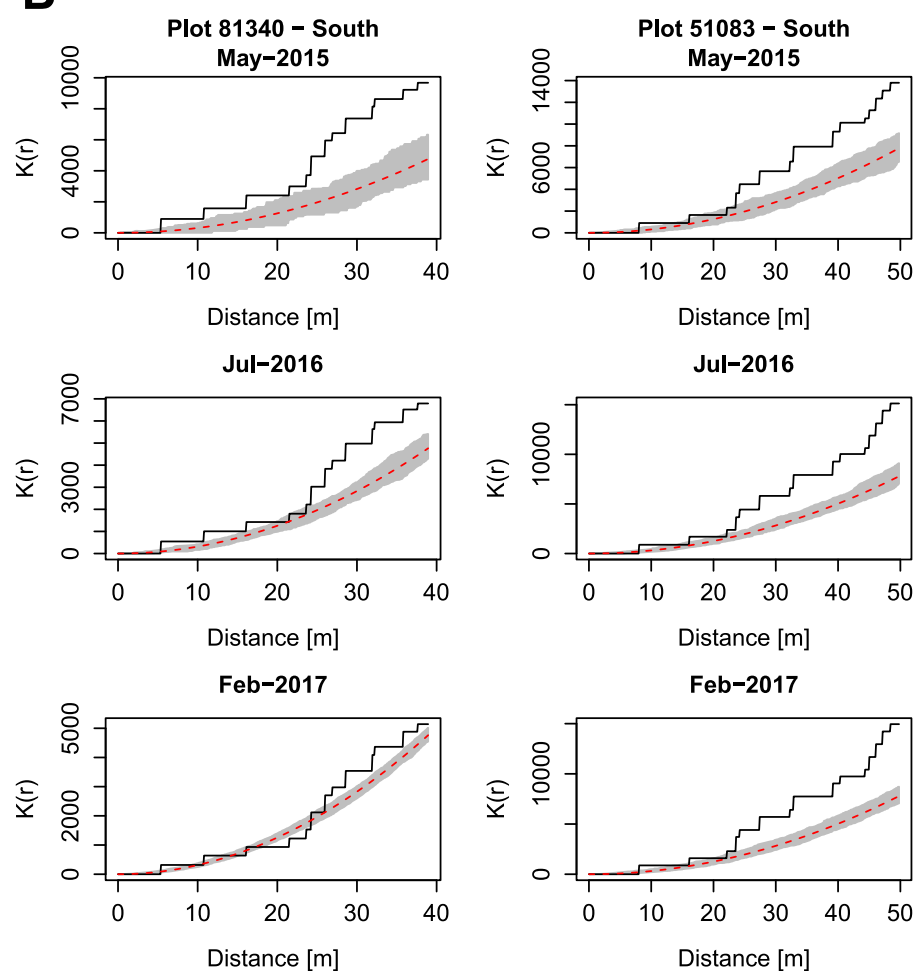

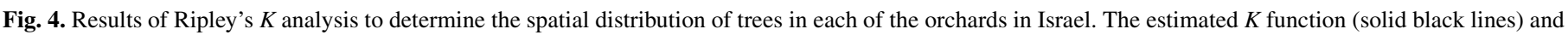

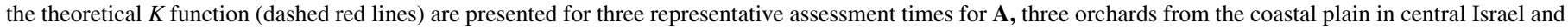

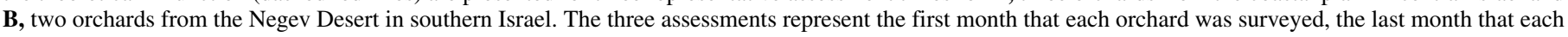

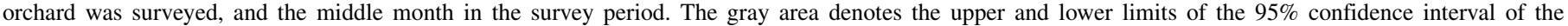
theoretical $K$ function. 
hoc test was performed. We used added-variable plots to visualize the relationship between the residuals of the dependent and the significant predictor variables while holding the other variables constant (Weisberg 2005). All statistical tests and figures were done using $\mathrm{R}$ version 3.3.0, and all results are reported as means \pm 1 standard error.

\section{RESULTS}

Spatial and temporal dynamics of the disease within orchards. The change in disease incidence over time. Of the seven surveyed orchards, only five orchards showed consistent increase in disease incidence over time (Fig. 2 and Supplementary Fig. S1). More specifically, three of the orchards from the coastal plain of Israel (Fig. 2A) $(6024,9080$, and 9694) and two of the orchards from the Negev Desert (Fig. 2B) (81340 and 51083) showed an increase in disease incidence over the course of the study.

Next, we focused on the five orchards that had an increase in disease incidence over time and calculated the rate of disease progression in each orchard. We assessed the change in disease incidence per orchard over the course of the study (Fig. 3A) and used logit transformation to calculate the rate of disease progression $(r)$, which is the slope of the change in the transformed data over time (Fig. 3B). The Tukey's post hoc test for multiple comparisons found significant differences in the rate of disease progression between orchards (Table 2). These results also indicate that there were months with no change in disease severity, and the timing of that static period varied among the surveyed orchards. In addition, it seems that disease also develop during winter months.

Spatial distribution pattern. Ripley's $K$ test characterized the pattern of spatial distribution of infected trees in the orchards for each of the months of the study (Fig. 4 and Supplementary Fig. S2). One orchard from the coastal plain of central Israel (Fig. 4A) (9694) and two orchards from southern Israel (Fig. 4B) (81340 and 51083) had clusters of infected trees. Orchard 9080 from central Israel showed a random distribution of infected trees, whereas the results for orchard 6024 were inconclusive (Fig. 4A).

Spatial dynamics. For those orchards with disease clusters, model selection was used to estimate whether there is a clear direction of disease spread over time. We built three models, each representing disease progression in a specific direction, and we chose a model based on three parameters: the amount of variation explained by the model as indicated by the $R^{2}$ value, the significance of the model as indicated by the $P$ value, and the relative quality of the model as indicated by the AIC (Table 3). For one orchard (81340), no model fit the data. For orchard 51340, the best model for explaining disease spread is the model assuming spread within rows of trees, and for the third orchard (9694), the best model is the one describing omnidirectional disease spread, although the model describing disease spread within rows was also significant.

Characterizing effects of cultural practices and environmental factors. Multiple regression model. Summary statistics for each of the explanatory variables are presented (Table 4). Because the number of explanatory variables is relatively high compared with the number of observations, we used methods of dimensionality reduction to choose the variables that best describe the variation in the data, and we created three multiple mixed effects linear regression models with estimated disease severity as the dependent variable and orchard identification as a random factor (Table 5). The Shapiro-Wilk normality test (LMG index model: $W=0.98, P=0.12$; varImp model: $W=0.98, P=0.17$; and combined model: $W=0.99, P=0.36$ ) and the QQ plots (Supplementary Fig. S3) confirmed that the residuals of each of these models distribute normally. Interestingly, all three models yielded the same results, with two explanatory variables having a significant effect on disease severity: cultivar and the area of urban terrain surrounding the orchard. More specifically, the citrus cultivar affected disease severity (Fig. 5) $\left(F_{3,50}=15.01, P<0.001\right)$, with cultivar Interdonato showing the lowest susceptibility to Mal Secco compared with cultivar Eureka Allen (Tukey's HSD $P=0.048$ ), but no differences were found between the other cultivars. However, when comparing Interdonato and Eureka Allen based on average orchard age, there was no statistical difference (one-way analysis of variance: $F_{1,27}=$ $2.9, P=0.098)$. A weak positive correlation $(r=0.27)$ was found between the total area of urban terrain in the 500-m radius surrounding each orchard and disease severity on trees in the orchard (Fig. 6) $\left(F_{1,50}=5.36, P=0.02\right)$.

\section{DISCUSSION}

We found that five of the seven orchards that were surveyed in the study showed a consistent increase in the number of Mal Seccodiseased trees over time, whereas two orchards (36030 and 8168) showed no significant change in the number of diseased trees. At the end of the study, we again visually inspected the orchards surveyed to assess the state of the disease in each of them and found that orchard 36030 showed no signs of Mal Secco disease, whereas orchard 8168 was indeed infected but showed no disease progression during the 3 years of the survey. These results might suggest that the agricultural practices used in orchard 8168 slowed or even stopped the disease from spreading. An alternative explanation would be that the environmental factors unique to this orchard played a role in preventing disease spread, but we find this less likely because the orchards are in the same geographical region, and the orchards were only a few kilometers apart, and the variation in environmental conditions is negligible.

There was an indication that agricultural practices affected disease spread. More specifically, orchards located only a few kilometers apart showed a fourfold difference in their rates of disease progress. One possible explanation for these differences is the citrus cultivar. Previous studies have demonstrated that susceptible cultivars have more rapid disease progression compared with resistant cultivars (Perrotta and Tribulato 1977). Another possible explanation would be the use of low-nitrogen manure, which is thought to slow progression of Mal Secco, especially when used in combination with appropriate doses of phosphorous and potassium (Nigro et al. 2011) (Y. Elad, unpublished results).

Previous epidemiological studies on Mal Secco disease have reported that there is no development of the disease during summer months, with development being renewed during the cooler late

TABLE 3. Logistic regression analysis of spread of Mal Secco disease in three citrus orchards in Israel showing results for the three models: (i) a model that describes disease spread within rows, (ii) a model that describes disease spread between rows, and (iii) a model that describes omnidirectional disease spread ${ }^{\mathrm{a}}$

\begin{tabular}{llll}
\hline Model & $P$ value & $R^{2}$ & AIC \\
\hline Center & & & \\
9694 & & & \\
Within rows & 0.001 & 0.34 & $2,229.0$ \\
Between rows & 0.0961 (NS) & 0.26 & $2,515.8$ \\
Omnidirectional & $<\mathbf{0 . 0 0 1}$ & $\mathbf{0 . 4 0}$ & $\mathbf{1 , 9 8 2 . 4}$ \\
South & & & \\
81340 & 0.666 (NS) & 0.28 & $2,903.3$ \\
Within rows & 0.186 (NS) & 0.23 & $3,101.5$ \\
Between rows & 0.414 (NS) & 0.30 & $2,686.1$ \\
Omnidirectional & & & \\
51340 & $\mathbf{0 . 0 0 1 2 2}$ & $\mathbf{0 . 2 7}$ & $\mathbf{2 , 8 1 2 . 9}$ \\
Within rows & 0.0368 & 0.14 & $3,322.4$ \\
Between rows & 0.948 (NS) & 0.26 & $2,865.1$ \\
Omnidirectional & &
\end{tabular}

a Parameters to gauge goodness of fit are the $P$ value, coefficient of determination $\left(R^{2}\right)$, and the Akaike information criterion (AIC) value calculated for each model. The model that best described the data for each orchard is indicated in bold. NS, not significant. 
summer and autumn (Grasso and Perrotta 1980; Nigro et al. 2011). The survey indicates that the timing of the static period varied among the surveyed orchards.

The values for the rate of disease progress $(r)$ were extremely low, indicating a slow rate of epidemic development (Van der Plank 1963). For example, an orchard with an $r$ of $0.003 /$ day and an initial disease incidence of $1 \%$ would be expected to attain a disease incidence of $27 \%$ after 3 years, or alternatively, an orchard with initial disease incidence of $10 \%$ will attain a disease incidence of $50 \%$ within 1.5 years (537 days). Still, these values should be viewed with caution for two reasons. First, these $r$ values were calculated based on field observations of disease progress, and the surveyed orchards were treated throughout the course of the study using sanitation pruning and fungicides. Thus, it is possible that the $r$ values are an underestimate of the true $r$ values that would be characteristic of the disease progress where there is no orchard management applied by growers. Second, growth of $P$. tracheiphilus is limited to specific months of the year when the temperatures are suitable: 15 to $21^{\circ} \mathrm{C}$ during periods of dispersal and host infection and 22 to $28^{\circ} \mathrm{C}$ during disease progression and fungal development (Migheli et al. 2009; Nigro et al. 2011). It was previously suggested that $r$ should be calculated based on accumulated day degrees (thermal time) during periods of optimal temperature for growth and development of the pathogen instead of a physical timescale (hours or days) (Lovell et al. 2004). It is possible that the rate of disease progression is underestimated because we assumed a constant rate throughout the study, whereas symptom development rate fluctuated.

Of the five orchards in which Mal Secco progressed, three orchards showed evidence of clusters of infected trees, although one orchard (9080) also showed a random distribution of diseased trees (Fig. 4 and Supplementary Fig. S2). The random distribution found in orchard 9080 suggests that there may be a different mechanism of pathogen dispersal in this orchard. Two nonmutually exclusive explanations are possible. (i) Different agricultural practices may have reduced disease spread between neighboring trees but did not prevent pathogen dispersal. (ii) $P$. tracheiphilus is known to penetrate the host using two distinct mechanisms: one through exposed wounds on the woody surfaces of the host and the second through exposed wounds on rootlets in the ground. It is possible that host penetration differed between these orchards. In this regard, host penetration through rootlets is characterized by accelerated disease progression compared with host penetration via the canopy (Migheli et al. 2009). The rate of disease progress $(r)$ in orchard 9080 is fourfold higher than the $r$ value of other orchards surveyed in the study (Table 2).

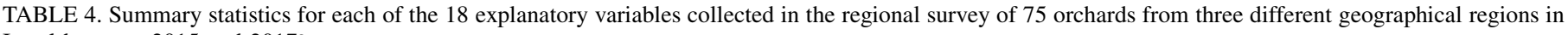
Israel between 2015 and $2017^{\mathrm{a}}$

\begin{tabular}{|c|c|c|c|}
\hline Region & North $(n=23)$ & Center $(n=26)$ & South $(n=26)$ \\
\hline Severity of Mal Secco (1-7) & $3.36 \pm 0.25$ & $2.65 \pm 0.24$ & $3.98 \pm 0.17$ \\
\hline Area $\left(\mathrm{m}^{2}\right)$ & $14,586.96 \pm 1,946.9$ & $8,096.15 \pm 1,110.1$ & $19,192.31 \pm 1,408.8$ \\
\hline Age (years) & $10.5 \pm 0.76$ & $20 \pm 1.02$ & $16.4 \pm 0.76$ \\
\hline Cultivar & Lime, Villa Franca & Interdonato, Villa Franca & Eureka Allen \\
\hline Rootstock & Khushkhash, Macrophylla, Volka & Khushkhash, Macrophylla, Volka & Khushkhash, Macrophylla, Volka \\
\hline Between lines (m) & $5.88 \pm 0.05$ & $5.17 \pm 0.08$ & $6.42 \pm 0.14$ \\
\hline Within lines $(\mathrm{m})$ & $3.29 \pm 0.08$ & $3.16 \pm 0.06$ & $3.52 \pm 0.06$ \\
\hline Irrigation lines (no.) & $1.00 \pm 0.00$ & $1.28 \pm 0.05$ & $1.21 \pm 0.06$ \\
\hline Precipitation (mm) & $46.6 \pm 1.99$ & $56.5 \pm 3.07$ & $33.3 \pm 1.7$ \\
\hline Elevation $(\mathrm{m})$ & $101 \pm 12.7$ & $33.7 \pm 1.09$ & $87.5 \pm 2.87$ \\
\hline Slope $(\mathrm{m})$ & $3.78 \pm 0.48$ & $3.04 \pm 0.61$ & $2.12 \pm 0.29$ \\
\hline Urban terrain $\left(\mathrm{m}^{2}\right)$ & $108,014.9 \pm 16,885.9$ & $123,489.6 \pm 12,586.5$ & $133,618.6 \pm 16,783.3$ \\
\hline Plantations $\left(\mathrm{m}^{2}\right)$ & $251,829.9 \pm 25,452.8$ & $299,142.2 \pm 23,350.0$ & $268,039.5 \pm 23,178.5$ \\
\hline Crop fields $\left(\mathrm{m}^{2}\right)$ & $195,459.5 \pm 23,543.2$ & $193,616.0 \pm 14,525.5$ & $242,573.9 \pm 20,197.7$ \\
\hline Soil $\left(\mathrm{m}^{2}\right)$ & $140,864.0 \pm 23,699.8$ & $117,669.8 \pm 11,052.8$ & $120,256.8 \pm 16,595.8$ \\
\hline Citrus $\left(\mathrm{m}^{2}\right)$ & $208,889.6 \pm 21,833.7$ & $286,261.8 \pm 15,488.8$ & $391,853.9 \pm 18,334.0$ \\
\hline Lemon orchards $\left(\mathrm{m}^{2}\right)$ & $32,112.02 \pm 2,992.9$ & $20,218.15 \pm 1,195.7$ & $77,410.88 \pm 5,458.5$ \\
\hline
\end{tabular}

${ }^{a}$ Data are presented as means \pm 1 standard error.

TABLE 5. Linear mixed effects regression models describing the effect of the explanatory variables on severity of Mal Secco disease on citrus in Israel ${ }^{\text {a }}$

\begin{tabular}{|c|c|c|c|c|c|c|}
\hline & \multicolumn{2}{|c|}{$\mathrm{LMG}$ index model ${ }^{\mathrm{b}}$} & \multicolumn{2}{|c|}{ varImp model ${ }^{\mathrm{c}}$} & \multicolumn{2}{|c|}{ Combined model $^{\mathrm{d}}$} \\
\hline & Coefficient & SE & Coefficient & SE & Coefficient & SE \\
\hline Intercept & 4.85 & 1.59 & 4.93 & 1.38 & 4.35 & 1.34 \\
\hline Variety (Interdonato) & -2.44 & 1.31 & -2.17 & 1.31 & -2.58 & 1.27 \\
\hline Variety (Lime) & -1.94 & 1.39 & -3.21 & 1.74 & -2.02 & 1.35 \\
\hline Variety (Villa Franca) & -0.69 & 0.49 & -0.61 & 0.52 & -0.79 & 0.45 \\
\hline Region (north) & 1.22 & 1.64 & 1.82 & 1.88 & 1.09 & 1.60 \\
\hline Region (south) & 0.722 & 1.35 & 0.60 & 1.30 & 0.49 & 1.27 \\
\hline Urban terrain & 0.000003 & 0.000001 & 0.000003 & 0.000001 & 0.000003 & 0.000001 \\
\hline Elevation & -0.0008 & 0.004 & 0.0001 & 0.01 & -0.001 & 0.003 \\
\hline Lemon area & -0.00001 & 0.000005 & -0.00001 & 0.00001 & -0.00001 & 0.000005 \\
\hline Precipitation & -0.004 & 0.007 & -0.01 & 0.01 & -0.004 & 0.01 \\
\hline Between lines & -0.115 & 0.18 & & & & \\
\hline Irrigation lines & & & -0.53 & 0.43 & & \\
\hline $\mathrm{AIC}^{\mathrm{e}}$ & \multicolumn{2}{|c|}{581.16} & \multicolumn{2}{|c|}{457.87} & \multicolumn{2}{|c|}{586.31} \\
\hline
\end{tabular}

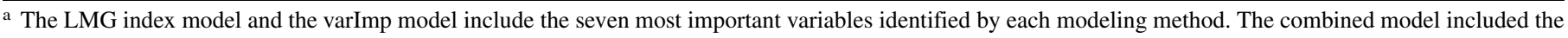
six overlapping variables between the two previous models. Variables having a significant effect $(P$ value $<0.05)$ are indicated in bold. SE, standard error.

b LGM index model: condition Variety + Region + Urban_Terrain + Elevation + Lemon_Area + Precipitation + Between_lines + (1|ID).

c varImp model: condition $\sim$ Variety + Region + Urban_Terrain + Elevation + Lemon_Area + Precipitation + irrigation_lines + (1|ID).

d Combined model: condition Variety + Region + Urban_Terrain + Elevation + Lemon_Area + Precipitation + (1|ID).

e AIC, Akaike information criterion. 
Another goal of the study was to assess whether disease spread has a clear direction of progression. The analysis of directionality in disease progression led us to conclude that at least two of the three orchards that have aggregated patterns of diseased tree also show evidence of disease spread within rows of trees (Table 3). This pattern of spatial dynamics is indicative of a contribution of agricultural practices to disease spread, and it is possible that the pathogen is carried from one tree to another by agricultural tools used during orchard management.

Citrus cultivar (Fig. 5) and the total area of urban terrain in the $500 \mathrm{~m}$ surrounding each orchard (Fig. 6) were two variables that were consistently significant with each of the multiple regression models used to describe the variation in disease severity over the time course of the study (Table 5). Specifically, disease severity is lower in orchards where Interdonato was grown compared with orchards where Eureka Allen was grown, although no differences were found between the remaining cultivars (Fig. 5). These results

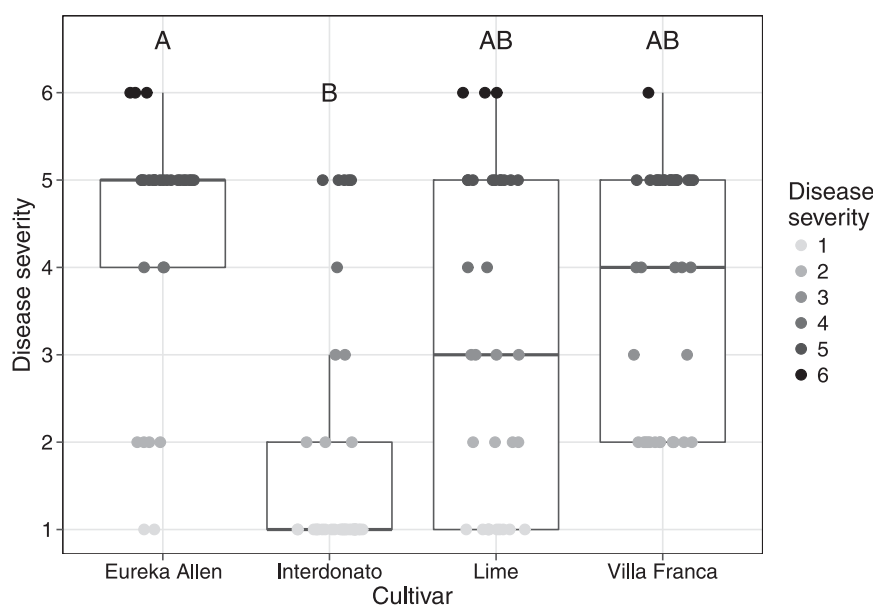

Fig. 5. The effect of citrus cultivar on severity of Mal Secco disease. The solid and bold black lines denote the median of disease severity for a given citrus cultivar, and the upper and lower limits of the box denote the 75 and $25 \%$ percentiles, respectively. The whiskers denote the interquartile range $(1.5 \times$ interquartile range). The circles denote an individual orchard, and the intensity of gray shade denotes disease severity as described in the legend. Bars with the same letter codes do not differ significantly (Tukey's honestly significant difference, $\alpha=0.05$ ).

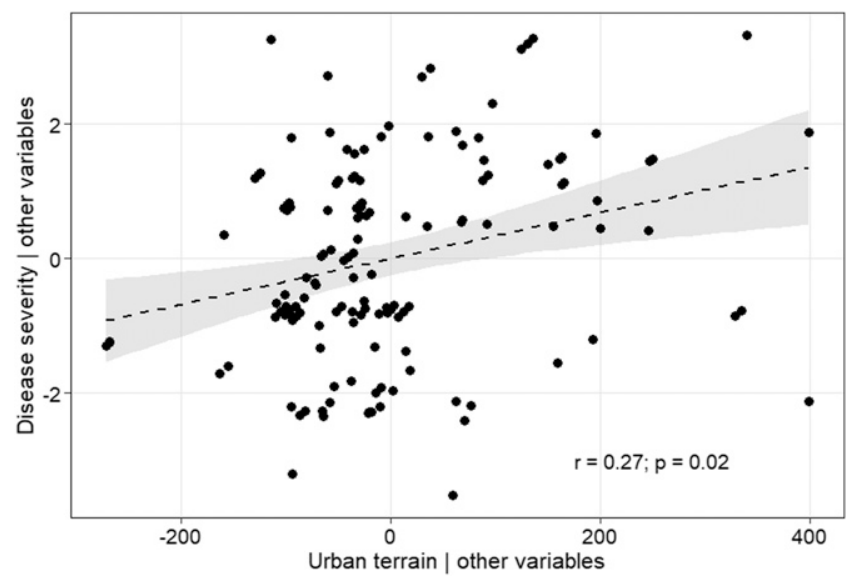

Fig. 6. Added variable plot depicting the correlation between the total area of urban terrain within the 500-m radius surrounding each orchard and disease severity of that orchard. The residuals of disease severity against the residuals of the total area of urban terrain surrounding each orchard are as calculated from the multiple regression model described in the text (the combined model is in Table 4). The correlation coefficient $(r)$ and the multiple regression model $P$ value are indicated. The gray shaded area denotes the standard error of the regression model. are consistent with those previously reported on the effect of scion cultivar of Mal Secco disease: cultivars Interdonato and Monachello are less susceptible to the disease compared with other cultivars (Solel and Oren 1975). However, although this study found differences in disease severity attributable to scion cultivar, there was no effect of rootstock genotype on disease severity (Table 4).

We also found a weak positive association $(r=0.27, P=0.02)$ between the total area of urban terrain in the $500 \mathrm{~m}$ surrounding each orchard and the severity of Mal Secco disease (Fig. 6). In a study on the pathogenic fungus Ceratocystis platani, the causal agent of canker stain of plane trees, it was found that inoculum concentration is higher in urban setting (Luchi et al. 2013). It was hypothesized that the intensive tree sanitation (pruning and felling) in urban environments caused an increase in airborne inoculum that is dispersed in the abundant sawdust that results (Luchi et al. 2013). In another study on medfly infesting citrus orchards, it was found that proximity to urban settlements is positively correlated with the size of the medfly population trapped in the orchards (Krasnov et al. 2019). The authors hypothesized that untreated trees in villages support pest reservoir that can infect nearby orchards. Yet, there is an important difference between these species and P. tracheiphilus, the fungus that causes Mal Secco disease. Unlike $C$. platani and medflies, $P$. tracheiphilus is waterborne. It is possible that untreated citrus trees in urban areas serve as an infection source; however, this explanation seems less likely in light of the data showing that $P$. tracheiphilus dispersal is limited to a few dozen meters (Tuttobene 1994). Furthermore, there is little evidence for the existence of the disease in private gardens in Israel (D. Ezra, unpublished data), and although birds and insects have been suggested as possible vectors allowing for longer-distance dispersal, this hypothesis has yet to be tested (Migheli et al. 2009). Thus, this observation needs to be interpreted with caution because the association was rather weak, and it may be that an additional uncharacterized factor is positively correlated with the total area of urban terrain.

An intriguing result from the study was the observation that there is no effect of the total area of lemon orchards surrounding an orchard on the severity of the disease (Table 5). These results refuted our hypothesis that there is a positive association between the total area of lemon orchards in the $500 \mathrm{~m}$ surrounding each orchard and disease severity, assuming that lemon orchards serve as a source of inoculum. In this regard, the dispersal distance of propagules of $P$. tracheiphilus is thought to be limited to 30 to $40 \mathrm{~m}$; the splashborne inoculum is carried by winds over short distances, probably within the borders of a single orchard (Tuttobene 1994).

\section{ACKNOWLEDGMENTS}

We thank the many growers for allowing the field technicians to survey their orchards and for providing us with valuable information regarding the orchard management practices used, information on the cultivars, etc. in the orchards. We also thank the three field scouts Avi Ziso, Robert Raskin, and Eli Shushan as well as Avi Sadovsky for his help with formulating the survey questions. Finally, we thank Dani Shtienberg for his comments on a first draft of this manuscript that helped improve its integrity tremendously. This work is a contribution of the Agricultural Research Organization, Volcani Center, Rishon Lezion, Israel (no. 589/18).

\section{LITERATURE CITED}

Aguayo, J., Elegbede, F., Husson, C., Saintonge, F.-X., and Marçais, B. 2014. Modeling climate impact on an emerging disease, the Phytophthora alniinduced alder decline. Glob. Change Biol. 20:3209-3221.

Atauri, J. A., and de Lucio, J. V. 2001. The role of landscape structure in species richness distribution of birds, amphibians, reptiles and lepidopterans in Mediterranean landscapes. Landsc. Ecol. 16:147-159.

Baddeley, A., Rubak, E., and Turner, R. 2015. Spatial Point Patterns: Methodology and Applications with R. Chapman and Hall/CRC, New York.

Bennie, J., Huntley, B., Wiltshire, A., Hill, M. O., and Baxter, R. 2008. Slope, aspect and climate: Spatially explicit and implicit models of topographic microclimate in chalk grassland. Ecol. Modell. 216:47-59. 
Blank, L., Birger, N., and Eizenberg, H. 2019a. Spatial and temporal distribution of Ecballium elaterium in almond orchards. Agronomy 9:751.

Blank, L., and Blaustein, L. 2012. Using ecological niche modeling to predict the distributions of two endangered amphibian species in aquatic breeding sites. Hydrobiologia 693:157-167.

Blank, L., and Blaustein, L. 2014. A multi-scale analysis of breeding site characteristics of the endangered fire salamander (Salamandra infraimmaculata) at its extreme southern range limit. Hydrobiologia 726:229-244.

Blank, L., Cohen, Y., Borenstein, M., Shulhani, R., Lofthouse, M., Sofer, M., et al. 2016. Variables associated with severity of bacterial canker and wilt caused by Clavibacter michiganensis subsp. michiganensis in tomato greenhouses. Phytopathology 106:254-261.

Blank, L., Linker, R., and Carmel, Y. 2013. A multiscale analysis of herbaceous species richness in a Mediterranean ecosystem. J. Plant Ecol. 6: 113-121.

Blank, L., Martín-García, J., Bezos, D., Vettraino, A. M., Krasnov, H., Lomba, J. M., et al. 2019b. Factors affecting the distribution of pine pitch canker in northern Spain. Forests 10:305.

Borchers, H. W., and Borchers, M. H. W. 2019. Package 'pracma' https:// cran.r-project.org/web/packages/pracma/index.html.

Campbell, C. L., and Madden, L. V. 1990. Introduction to Plant Disease Epidemiology. John Wiley \& Sons, New York, NY.

Cutuli, G. 1985. Malattie crittogamiche e alterazioni da cause non parassitarie. Trattato Agrumic. 2:23-102.

De Cicco, V., Paradies, M., Cutuli, G., and Salerno, M. 1984. Pages 218-221 in: The Role of Mal Secco Infected Lemon Twigs and Leaves Left on the Ground in Root Infection in Cairo, Egypt.

De Gruyter, J., Woudenberg, J. H. C., Aveskamp, M. M., Verkley, G. J. M., Groenewald, J. Z., and Crous, P. W. 2013. Redisposition of phoma-like anamorphs in Pleosporales. Stud. Mycol. 75:1-36.

EPPO CABI. 1997. Deuterophoma tracheiphila. Pages 733-736 in: Quarantine Pests for Europe, 2nd ed. CAB International, Wallingford, U.K.

Ezra, D., Kroitor, T., and Sadowsky, A. 2007. Molecular characterization of Phoma tracheiphila, causal agent of Mal secco disease of citrus, in Israel. Eur. J. Plant Pathol. 118:183-191.

Firester, B., Shtienberg, D., and Blank, L. 2018. Modeling the spatio-temporal dynamics of Phytophthora infestans at a regional scale. Plant Pathol. 67: 1552-1561.

Fisher, M. A., and Fulé, P. Z. 2004. Changes in forest vegetation and arbuscular mycorrhizae along a steep elevation gradient in Arizona. For. Ecol. Manage. 200:293-311.

Food and Agriculture Organization of the United Nations. 2016. Worldwide lemon production in tonnes. http://www.fao.org/faostat/en/\#data/QC

Goldreich, Y. 2003. The Climate of Israel: Observation, Research and Application. Springer, New York, NY.

Grasso, S., and Perrotta, G. 1980. Variazioni stagionali nella germinabilita delle picnidiospore di Phoma tracheiphila. Rivista di Patologia Vegetale 16: 19-24.

Grömping, U. 2006. Relative importance for linear regression in R: The package relaimpo. J. Stat. Softw. 17:1-27.

Gulsen, O., Uzun, A., Pala, H., Canihos, E., and Kafa, G. 2007. Development of seedless and Mal Secco tolerant mutant lemons through budwood irradiation. Sci. Hortic. (Amsterdam) 112:184-190.

Hall, J. K. 2008. The 25-m DTM (digital terrain model) of Israel. Isr. J. Earth Sci. 57:145-147.

Krasnov, H., Cohen, Y., Goldshtein, E., Mendelsohn, O., Silberstein, M., Gazit, Y., et al. 2019. The effect of local and landscape variables on Mediterranean fruit fly dynamics in citrus orchards utilizing the ecoinformatics approach. J. Pest Sci. 92:453-463.

Kuhn, M. 2015. Caret: Classification and Regression Training. Astrophysics Source Code Library. https://cran.r-project.org/web/packages/caret/index. html

Lamichhane, J. R., Fabi, A., and Varvaro, L. 2014. Summer heat and low soil organic matter influence severity of hazelnut cytospora canker. Phytopathology 104:387-395.

Lenth, R., and Lenth, M. R. 2018. Package '1smeans'. Am. Stat. 34:216-221.

Licciardello, G., Grasso, F. M., Bella, P., Cirvilleri, G., Grimaldi, V., and Catara, V. 2006. Identification and detection of Phoma tracheiphila, causal agent of citrus Mal Secco disease, by real-time polymerase chain reaction. Plant Dis. 90:1523-1530.

Lindeman, R. H., Merenda, P. F., and Gold, R. Z. 1980. Introduction to Bivariate and Multivariate Analysis. Glenview, IL: Scott, Foresman.

Lovell, D. J., Powers, S. J., Welham, S. J., and Parker, S. R. 2004. A perspective on the measurement of time in plant disease epidemiology. Plant Pathol. 53:705-712.
Luchi, N., Ghelardini, L., Belbahri, L., Quartier, M., and Santini, A. 2013. Rapid detection of Ceratocystis platani inoculum by quantitative real-time PCR assay. Appl. Environ. Microbiol. 79:5394-5404.

Marmen, S., Aharonovich, D., Grossowicz, M., Blank, L., Yacobi, Y. Z., and Sher, D. J. 2016. Distribution and habitat specificity of potentially-toxic microcystis across climate, land, and water use gradients. Front. Microbiol. $7: 271$.

Meentemeyer, R. K., Haas, S. E., and Václavík, T. 2012. Landscape epidemiology of emerging infectious diseases in natural and human-altered ecosystems. Annu. Rev. Phytopathol. 50:379-402.

Migheli, Q., Cacciola, S. O., Balmas, V., Pane, A., Ezra, D., and di San Lio, G. M. 2009. Mal secco disease caused by Phoma tracheiphila: A potential threat to lemon production worldwide. Plant Dis. 93:852-867.

Naimi, B., Hamm, N. A., Groen, T. A., Skidmore, A. K., and Toxopeus, A. G. 2014. Where is positional uncertainty a problem for species distribution modelling? Ecography 37:191-203.

Nigro, F., Ippolito, A., and Salerno, M. G. 2011. Mal secco disease of citrus: A journey through a century of research. J. Plant Pathol. 93:523-560.

Neter, J., Wasserman, W., and Kutner, M. H. 1989. Applied Linear Regression Models. Irwin, Homewood, IL.

Ostfeld, R. S., Glass, G. E., and Keesing, F. 2005. Spatial epidemiology: An emerging (or re-emerging) discipline. Trends Ecol. Evol. 20:328-336.

Perrotta, G., and Tribulato, E. 1977. Observation on the susceptibility of nucellar lines of lemon to mal secco disease in Sicily. Pages 1004-1005 in: Proceedings of the International Society of Citriculture, Orlando, FL.

Plantegenest, M., Le May, C., and Fabre, F. 2007. Landscape epidemiology of plant diseases. J. R. Soc. Interface 4:963-972.

R Core Development Team. 2014. R: A Language and Environment for Statistical Computing. R Foundation for Statistical Computing, Vienna, Austria.

Raciti, G., Cutuli, G., Intrigliolo, F., and Giuffrida, A. 1990. Indagini sull'influenza delle tecniche colturali sul mal secco degli agrumi. Inf. Agrar. 41:61-64.

Ripley, B. D. 1976. The second-order analysis of stationary point processes. J. Appl. Probab. 13:255-266.

Ruggieri, G. 1948. Fattori che condizionano o contribuiscono allo sviluppo del "mal secco" degli agrumi e metodi di lotta contro il medesimo. Ann. Della Sper. Agrar. 2:255-305.

Russo, M., Grasso, F. M., Bella, P., Licciardello, G., Catara, A., and Catara, V. 2009. Molecular diagnostic tools for the detection and characterization of Phoma tracheiphila. Acta Hortic. 892:207-214.

Schloerke, B., Crowley, J., Cook, D., Hofmann, H., Wickham, H., Briatte, F., et al. 2011. Ggally: Extension to ggplot2. https://cran.r-project.org/web/ packages/GGally/index.html

Shtienberg, D. 1996. Variables associated with intensity of Alternaria leaf spot in Pima cotton. Phytopathology 86:123-128.

Solel, Z., and Oren, Y. 1975. Outbreak of mal secco disease in Israel on normally tolerant citrus cultivars. Plant Dis. Rep. 59:945-946.

Solel, Z., and Spiegel-Roy, P. 1978. Methodology of selection of lemon clones for tolerance to Mal Secco (Phoma Tracheiphila). Phytoparasitica 6: 129-134.

Sparks, A. H., Esker, P. D., Antony, G., Campbell, L., Frank, E. E., Huebel, L., et al. 2008. Ecology and epidemiology in R: Spatial pattern analysis. https:// vtechworks.lib.vt.edu/handle/10919/67373

Talley, S. M., Coley, P. D., and Kursar, T. A. 2002. The effects of weather on fungal abundance and richness among 25 communities in the Intermountain West. BMC Ecol. 2:7.

Thébaud, G., Sauvion, N., Chadœuf, J., Dufils, A., and Labonne, G. 2006. Identifying risk factors for European stone fruit yellows from a survey. Phytopathology 96:890-899.

Traversa, E., Ippolito, A., and De Cicco, V. 1992. Epidemiological investigation on Citrus Mal secco (Phoma tracheiphila). Presence of the pathogen in the leaves of infected twigs. Phytopathol. Mediterr. 31:103-106.

Tuttobene, R. 1994. Monitoring of Phoma tracheiphila inoculum. Difesa Delle Piante. 17:69-74.

Van der Plank, J. E. 1963. Plant Diseases-Epidemics and Control. Academic Press, New York.

Weisberg, S. 2005. Applied Linear Regression. John Wiley \& Sons, Hoboken, NJ.

Wickham, H. 2010. stringr: Modern, consistent string processing. R J. 2:38-40.

Wickham, H. 2016. ggplot2: Elegant Graphics for Data Analysis. Springer, New York.

Wickham, H., and Henry, L. 2017. Tidyr: Easily tidy data with 'spread ()'and 'gather ()'functions. R Package Version 06. https://cran.r-project.org/web/ packages/tidyr/index.html 